\title{
Absolute gravity change associated with the March 1997 earthquake swarm in the Izu Peninsula, Japan
}

\author{
Shigeo Yoshida ${ }^{1 *}$, Gaku Seta $^{1}$, Shuhei Okubo $^{1}$, and Shigeki Kobayashi ${ }^{2}$ \\ ${ }^{1}$ Earthquake Research Institute, University of Tokyo, 1-1-1 Yayoi, Bunkyo-ku, Tokyo 113-0032, Japan \\ ${ }^{2}$ Earth Observation Research Center, National Space Development Agency of Japan, Roppongi First BLDG $13 F$, \\ 1-9-9 Roppongi, Minato-ku, Tokyo 106-0032, Japan
}

(Received March 26, 1998; Revised October 6, 1998; Accepted October 7, 1998)

\begin{abstract}
We carried out both absolute and relative gravity measurements in the Izu Peninsula just before and after the March 1997 earthquake swarm occurred. The measurements revealed significant absolute gravity changes, which we find to be made of three spatial components. The first one is located near Cape Kawana, and would be associated with the volcanic activity that caused the earthquake swarm. The second one would be associated with shallow and localized magma intrusion just beneath Ito. The third one may be due to a change in the deep region beneath the Kita-Izu fault system, which is considered to be a major tectonic line of this region. The gravity changes can be used to detect underground mass movement. For this purpose, we first use crustal movement observations to construct an elastic dislocation model with two tensile faults and a left lateral fault. Then we use the gravity changes to constrain the density of the material which filled the tensile faults. We find that the density is likely to be small, and that the gravity changes of the first component are reproduced well by the fault model. The smallness of the density implies that highly vesiculated magma or water would have injected into the faults.
\end{abstract}

\section{Introduction}

Earthquake swarms occur once or twice a year around the eastern coast of the Izu Peninsula (Fig. 1) (e.g. Hori, 1989; Mogi, 1991) since 1978, when the Izu-Oshima-Kinkai-Oki earthquake (M7.0) broke out. They are often accompanied by crustal deformation around Ito (Fig. 1(a)).

The relation between earthquake swarms and monogenetic volcanos in this area has long been discussed because of the near similar location of the epicenters and the Higashi-Izu monogenetic volcano group. The connection was evidenced by the sequence of 1989 earthquake swarm and the TeishiKnoll submarine eruption (see the special issue of $J$. Phys. Earth, Vol. 39, No. 1 for details), which may be regarded as Higashi-Izu volcano group activity. Discussion on the relation between swarms and volcanism dates back to 1930, when an earthquake swarm occurred around eastern Izu. Imamura Laboratory and Seismological Laboratory (1930), Ishimoto and Takahashi (1930), and Nasu (1930, 1935) suggested a magmatic origin of the swarm and the associated crustal uplift. Tsuya (1930) and Kuno (1954) discussed its relation to geological structure. Aramaki and Hamuro (1977) reported the connection between volcanism around Izu and 19751976 swarms. The relation between swarms and volcanism has often been discussed since earthquake swarms became frequent in 1978.

* Present affiliation: Department of Earth and Planetary Sciences, School of Science, Nagoya University, Furo-cho, Chikusa-ku, Nagoya 464-8602, Japan.

Copy right $(\mathrm{C}$ The Society of Geomagnetism and Earth, Planetary and Space Sciences (SGEPSS); The Seismological Society of Japan; The Volcanological Society of Japan; The Geodetic Society of Japan; The Japanese Society for Planetary Sciences.
An earthquake swarm started on March 3, 1997, and continued for about three weeks. The source area was off Shiofuki-zaki at the beginning of March 3, and then migrated to off Kawana-zaki at about 0800 LT March 3 (Fig. 1). The activity declined with time and nearly ended in about a week (Earthquake Research Institute, 1997; Japan Meteorological Agency, 1997). The total number of the earthquakes recorded at Kamata, Ito City, from 3 to 26 March was 9334 according to Japan Meteorological Agency (1997). The number of the earthquakes larger than M5.0 was 4. They occurred during the early stage on March 3 and 4. The mechanisms of most of the earthquakes are strike-slip type with the P-axis in the NW-SE direction, which is in accord with the regional stress field (e.g. Tsukahara and Ikeda, 1987). This stress pattern, the $\mathrm{P}$-axis being in the NW-SE direction, is interpreted in terms of the collision of the Philippine Sea plate against the Japan Island (e.g. Ukawa, 1991; Koyama and Umino, 1991) or the bending of the slab (Nakamura et al., 1984).

Many kinds of measurements of crustal movement have been carried out around Ito, including GPS, leveling (Geographical Survey Institute, 1997), and EDM (Tsuneishi, 1997), in order to clarify the mechanism of earthquake swarms. During the March swarm, movements showed complex spatial variation, which we examine in Section 3.

Gravity measurements are complementary to these geometrical observations of crustal movement in that they can detect underground mass movement. For revealing magma or fluid motion which would cause earthquake swarms, our group has carried out gravity measurements once or twice a year since 1974, when the Izu-Hanto-Oki earthquake (M6.9) occurred. The results from 1974 to 1985 were summarized by Hagiwara et al. (1985). They reported significant gravity 


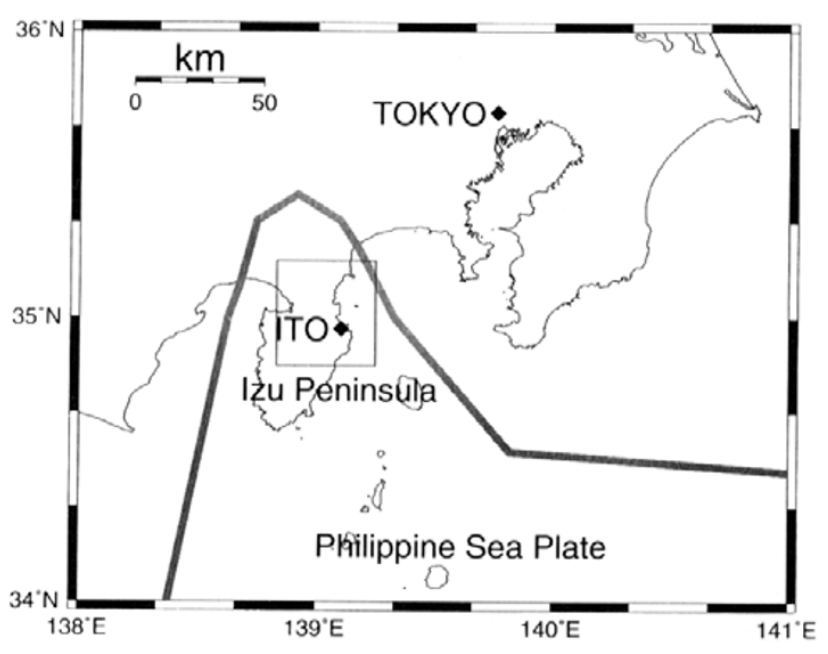

(a)

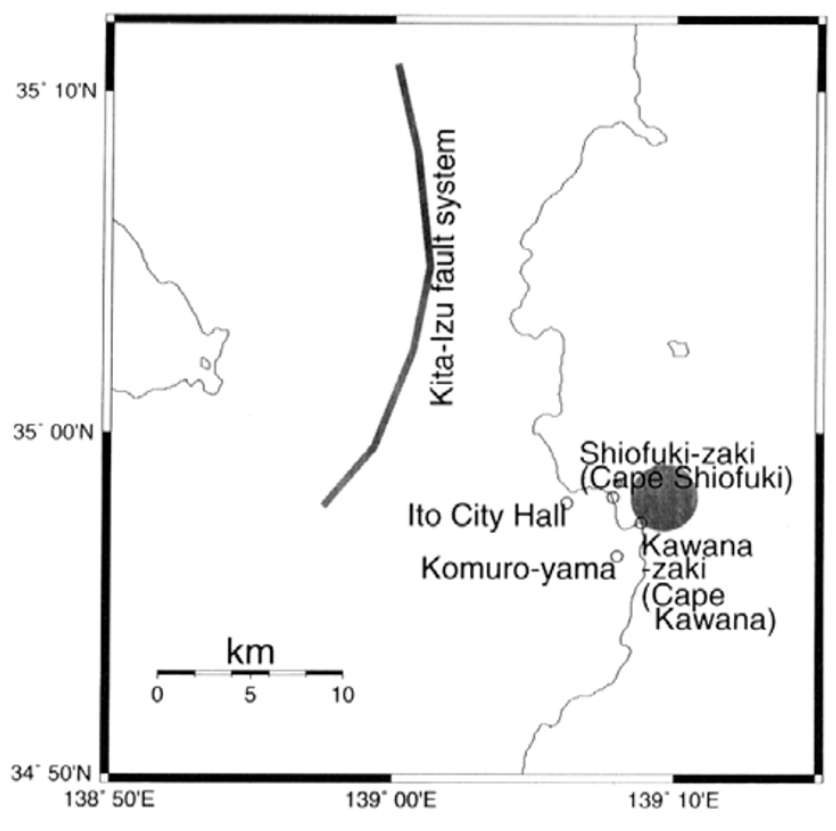

(b)

Fig. 1. Index map of the study area. (a) Map of the South Kanto area. The gray line represents the boundary of the Philippine Sea Plate. The inset rectangle indicates the area of Fig. 1(b). (b) Map of the north-eastern part of the Izu Peninsula. The shaded circle represents the central region of the earthquake swarm activity in March 1997.

Table 1. Details of the absolute gravity measurements.

\begin{tabular}{lrr}
\hline & Before the swarm & After the swarm \\
\hline Measurement dates & February 3, 5-7, 1997 & March 8-14, 1997 \\
Absolute gravity value $(\mu$ gal $)$ & $979798779.1 \pm 0.3$ & $979798775.0 \pm 0.3$ \\
Number of total effective drops & 10,162 & 20,259 \\
Standard deviation of a drop $(\mu \mathrm{gal})$ & 34 & 37 \\
Pole tide $(\mu \mathrm{gal})$ & 0.2 & 0.4 \\
\hline
\end{tabular}

changes due to large earthquakes. Okubo et al. (1991) detected gravity changes caused by the 1989 earthquake swarm and the associated submarine eruption of Teishi Knoll. They interpreted the changes in terms of an elastic deformation due to a tensile fault, a strike-slip fault and an inflation source. All these measurements before 1997 were performed with only LaCoste-Romberg gravimeters, which allowed them to detect only relative gravity changes.

Absolute gravimetry is required to measure temporal gravity changes unequivocally. For this purpose, our group introduced an absolute gravimeter FG5 (\#109) (Niebauer et al., 1995) in 1994 (Okubo et al., 1997). We measured the absolute gravity in Ito in February 1997, only a month before the swarm in March. The measurement along with that in March 1997 enabled us to detect absolute gravity changes associated with the earthquake swarm activity. This is the first attempt to measure absolute gravity changes of seismic and volcanic origins. We present the results together with their interpretation in the following.

\section{Gravity Measurements}

\subsection{Absolute gravity measurements}

We installed the FG5 absolute gravimeter in the Ito City Hall to establish the reference point for our precise gravity network. A gravity decrease of $4 \mu$ gal was detected there after the earthquake swarm compared with the value of a month before. This value is used as the reference of gravity changes measured by a LaCoste-Romberg gravimeter. The results of the relative measurements are described in Subsection 2.2.

The results of the absolute gravity observations and their details are summarized in Table 1. The absolute measurements are corrected for the instrumental height, the solid earth tide, the pole tide, and the atmospheric pressure. The gravity values are reduced to those at the height of $130 \mathrm{~cm}$ above the floor with a gravity gradient of $-2.85 \mu \mathrm{gal} / \mathrm{cm}$. The solid earth tide is corrected with the tidal gravity factor $\delta=1.164$, except for the permanent tide, for which $\delta=1.0$ is used. The barometric correction was made with a standard air pressure of $1007.3 \mathrm{hPa}$ and an admittance of $0.3 \mu \mathrm{gal} / \mathrm{hPa}$. The standard error of each absolute gravity 
Table 2. Gravity data before and after the earthquake swarm and their difference $\Delta g . g$ is the gravity values relative to that of the Ito City Hall in February in the unit of $\mu$ gal. Add $979799149.6 \mu$ gal (absolute gravity at the floor in the Ito City Hall in February) to $g$ to obtain the absolute gravity values in February and March. $\epsilon$ denotes the estimated observational error in the unit of $\mu$ gal. The method of the error estimation is described in the text. $N$ is the number of relative gravity measurements carried out at each site. At least two measurements were performed at each site because we used two-way method. The multiple measurements at each point are used to correct the instrumental drift and to improve the error. The location of the sites are mapped on Fig. 2(b). The data of the sites indicated by asterisks are not used in estimating the densities of the materials intruding into tensile faults in Section 3.

\begin{tabular}{|c|c|c|c|c|c|c|c|c|c|c|}
\hline \multirow[t]{2}{*}{ Site name } & \multirow{2}{*}{$\begin{array}{l}\text { Latitude } \\
\text { (deg.) }\end{array}$} & \multirow{2}{*}{$\begin{array}{l}\text { Longitude } \\
\text { (deg.) }\end{array}$} & \multicolumn{3}{|c|}{ February $6,17-21$} & \multicolumn{3}{|c|}{ March 8-14 } & \multicolumn{2}{|c|}{ Change } \\
\hline & & & $g$ & $\epsilon$ & $N$ & $g$ & $\epsilon$ & $N$ & $\Delta g$ & $\epsilon$ \\
\hline Ito-City-Hall (Reference) & 34.9623 & 139.1047 & 0 & & 5 & -4 & & 6 & -4 & \\
\hline Ito-CityBM & 34.9625 & 139.1045 & -316 & 4 & 11 & -326 & 3 & 32 & -10 & 5 \\
\hline BM-9402 & 35.0417 & 138.9057 & $-2,553$ & 9 & 4 & $-2,561$ & 7 & 2 & -8 & 11 \\
\hline BM-9328 & 35.0588 & 139.0742 & 7,951 & 8 & 2 & 7,942 & 8 & 2 & -9 & 11 \\
\hline BM-9330 & 35.0457 & 139.0978 & 10,665 & 8 & 2 & 10,660 & 8 & 2 & -5 & 11 \\
\hline BM-9332 & 35.0075 & 139.0918 & 3,671 & 8 & 2 & 3,669 & 8 & 2 & -2 & 11 \\
\hline BM-9334 & 34.9765 & 139.0965 & 5,476 & 5 & 11 & 5,475 & 5 & 4 & -1 & 7 \\
\hline BM-9335 & 34.9647 & 139.1037 & 6,107 & 8 & 2 & 6,095 & 7 & 2 & -12 & 11 \\
\hline BM-9336* & 34.9517 & 139.1123 & $-15,920$ & 8 & 2 & $-15,903$ & 6 & 4 & 17 & 10 \\
\hline BM-9337 & 34.9400 & 139.1212 & $-20,132$ & 5 & 4 & $-20,146$ & 8 & 2 & -14 & 9 \\
\hline BM-9340 & 34.8933 & 139.1233 & $-32,326$ & 7 & 2 & $-32,337$ & 8 & 2 & -11 & 11 \\
\hline BM-9341 & 34.8753 & 139.1068 & $-14,930$ & 7 & 2 & $-14,936$ & 8 & 2 & -6 & 11 \\
\hline BM-9344 & 34.8402 & 139.0790 & -367 & 7 & 2 & -370 & 8 & 2 & -3 & 11 \\
\hline BM-10005 & 34.9020 & 139.0437 & $-129,590$ & 10 & 2 & $-129,591$ & 5 & 4 & -1 & 11 \\
\hline BM-003-002 & 34.9538 & 139.0863 & $-10,154$ & 10 & 2 & $-10,158$ & 7 & 2 & -4 & 12 \\
\hline BM-003-005 & 34.9470 & 139.0785 & $-45,667$ & 10 & 2 & $-45,671$ & 7 & 2 & -4 & 12 \\
\hline BM-003-006 & 34.9460 & 139.0703 & $-60,795$ & 10 & 2 & $-60,798$ & 6 & 4 & -3 & 12 \\
\hline BM-003-007 & 34.9487 & 139.0650 & $-60,700$ & 10 & 2 & $-60,710$ & 7 & 2 & -10 & 12 \\
\hline BM-003-012 & 34.9438 & 139.0270 & $-40,047$ & 8 & 7 & $-40,055$ & 6 & 4 & -8 & 10 \\
\hline BM-003-017* & 34.9623 & 138.9822 & $-26,215$ & 9 & 2 & $-26,228$ & 7 & 2 & -13 & 11 \\
\hline Hatsushima-Port & 35.0392 & 139.1723 & $-2,274$ & 9 & 2 & $-2,278$ & 8 & 2 & -5 & 12 \\
\hline Hatsuki-Shrine & 35.0393 & 139.1725 & $-3,851$ & 9 & 2 & $-3,858$ & 8 & 2 & -7 & 12 \\
\hline Fishery Radio Station & 34.9613 & 139.1217 & $-40,938$ & 6 & 2 & $-40,839$ & 5 & 6 & -1 & 8 \\
\hline Kawana-Suwa & 34.9492 & 139.1407 & 10,119 & 6 & 2 & 10,102 & 6 & 4 & -17 & 8 \\
\hline Nakaizu* & 34.9870 & 139.0385 & $-113,195$ & 9 & 2 & $-113,225$ & 6 & 4 & -30 & 11 \\
\hline Kameishi* & 35.0203 & 139.0462 & $-92,158$ & 9 & 2 & $-92,175$ & 6 & 4 & -17 & 11 \\
\hline Atami-Pass* & 35.1168 & 139.0422 & $-124,403$ & 9 & 2 & $-124,425$ & 7 & 2 & -22 & 11 \\
\hline 10KM-PostBM ${ }^{*}$ & 35.0610 & 139.0377 & $-123,068$ & 9 & 2 & $-123,085$ & 7 & 2 & -17 & 11 \\
\hline
\end{tabular}

value is about $0.3 \mu \mathrm{gal}$, the standard deviation of a single drop divided by the square root of the number of drops. The 1-2 $\mu$ gal precision of the FG5 gravimeter was confirmed in advance by Okubo et al. (1997) by detecting gravity signals due to the ocean tide.

\subsection{Relative gravity measurements}

We used a LaCoste-Romberg gravimeter (G-581) to measure precise relative gravity changes around Ito. The measurements were carried out on February 6, 17-21, 1997, before the earthquake swarm and on March 8-14 after the swarm. Relative gravity is measured as the differences from the value at the Ito City Hall, so that the absolute values for all sites can be obtained by adding the differences to the absolute value measured with FG5 (Table 2). The two-way method was taken to correct the instrumental drift and to ensure the precision. We estimated the observational errors as 5-10 $\mu$ gal from the two-way repeatability as tabulated in Table 2. We removed the systematic cyclic error (Becker et 


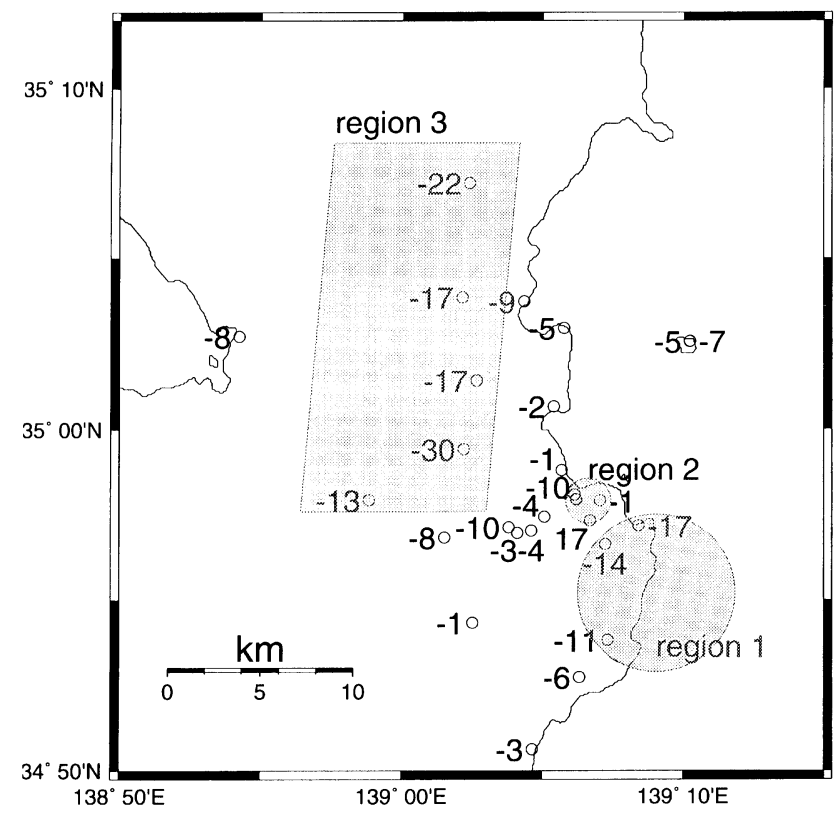

(a)

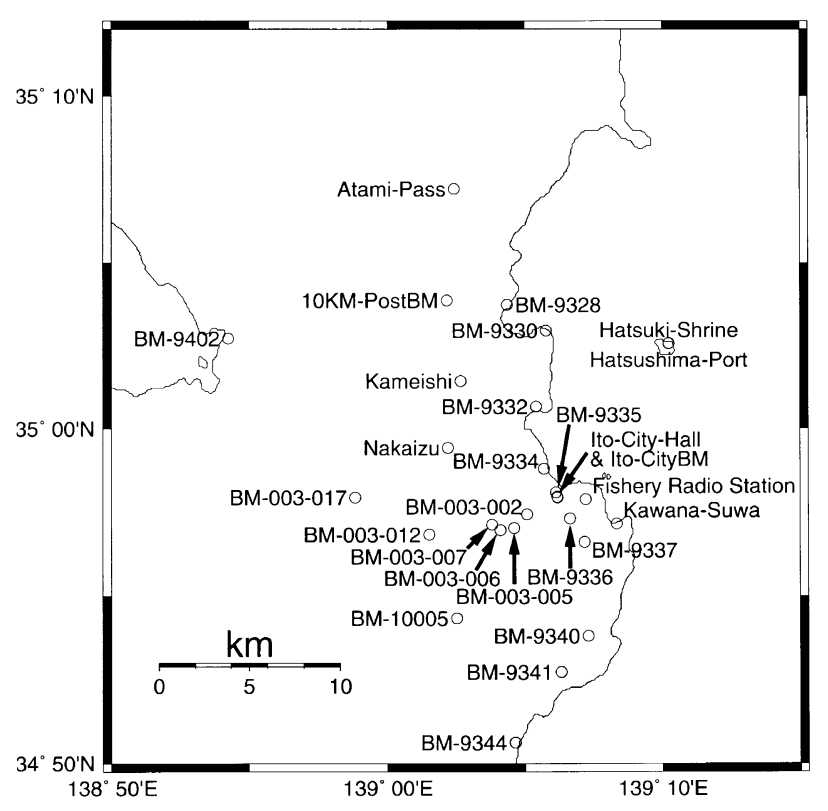

(b)

Fig. 2. (a) Absolute gravity changes between February and March 1997 measured with an FG5 absolute gravimeter and a LaCoste-Romberg gravimeter. The unit is $\mu$ gal. The details are given in Table 2 . The precisions are 5-10 $\mu$ gal. The shaded areas indicate the regions where significant gravity changes were observed. (b) Site map of relative gravity measurements.

al., 1987) and the magnetic error (e.g. Torge, 1989) inherent in any LaCoste-Romberg gravimeter to attain the precision.

The error at each point is estimated as follows. We define the two-way repeatability as a half of the maximum vaule of the deviations of the two-way differences from the linear drift in one set of two-way measurements. The error at each site is first estimated as the two-way repeatability defined above if it is larger than $5 \mu$ gal. The error is set to be $5 \mu$ gal if the twoway repeatability is less than $5 \mu$ gal. Then we apply network adjustment to the whole sets of two-way measurements to estimate internally consistent gravity values and their error covariances. The errors shown in Table 2 are derived from these covariances.

Figure 2 shows the absolute gravity changes between February and March 1997. We find three areas where the gravity changes amount to more than about $10 \mu$ gal. (regions 1, 2, and 3 in Fig. 2(a)). In the region 1 near Kawana-zaki, we observed gravity decreases up to $17 \mu$ gal. The decreases are explained well by elastic deformation due to strike-slip and tensile faulting. The elastic model is elaborated in the next section. The region 2 is located in the Ito City to the northwest of the first region. It is characterized by rather localized and complicated changes up to about $10 \mu \mathrm{gal}$. The changes would be caused by small dikes intruding into the very shallow part of the crust. It could otherwise be due to observational errors, because of the rather noisy environment near the observation sites BM-9336 and BM-9337. The region 3 is located in the mountainous area around the neck of the Izu Peninsula. It is characterized by large gravity decreases up to $30 \mu \mathrm{gal}$. The gravity changes would be related to the Kita-Izu fault system. The tectonic implication will be discussed in Section 4.

\section{Fault Model}

A quantitative approach to model gravity changes due to seismic activity is given by Okubo $(1991,1992)$. He derived analytical expressions for gravity changes caused by faulting and inflation sources. In his theory, gravity changes arise from three sources, namely, density changes due to elastic deformation, surface uplift or subsidence, and the addition of mass. To reveal mass movement, we should first find fault parameters to calculate the other two sources. Then we subtract their contributions from observed gravity changes to find masses of added materials.

\subsection{Determination of fault parameters}

First, we apply Okada (1985)'s elastic dislocation theory to the ground displacements around Ito associated with the March 1997 activity to determine the fault geometry. Similar methods were used by Okada and Yamamoto (1991a,b), Tada and Hashimoto (1991), and Okubo et al. (1991) to simulate the crustal displacements associated with the 1989 activity. We use GPS observations, leveling, and EDM data (Geographical Survey Institute, 1997; Tsuneishi, 1997) for the modeling.

The positions of about 10 points near Ito have been continuously monitored by the nationwide GSI's GPS network (Fig. 3). The measurements pose strong constraints on horizontal movement. Figure 3 shows horizontal displacements associated with the earthquake swarm. The stations to the south of the swarm epicenters moved to the SW direction and those to the north moved to the SE and NE directions. In particular, the Komuro-yama station, which is the nearest to the epicenters, moved to the SW direction by as much as $10 \mathrm{~cm}$.

The leveling survey was carried out in October-November 


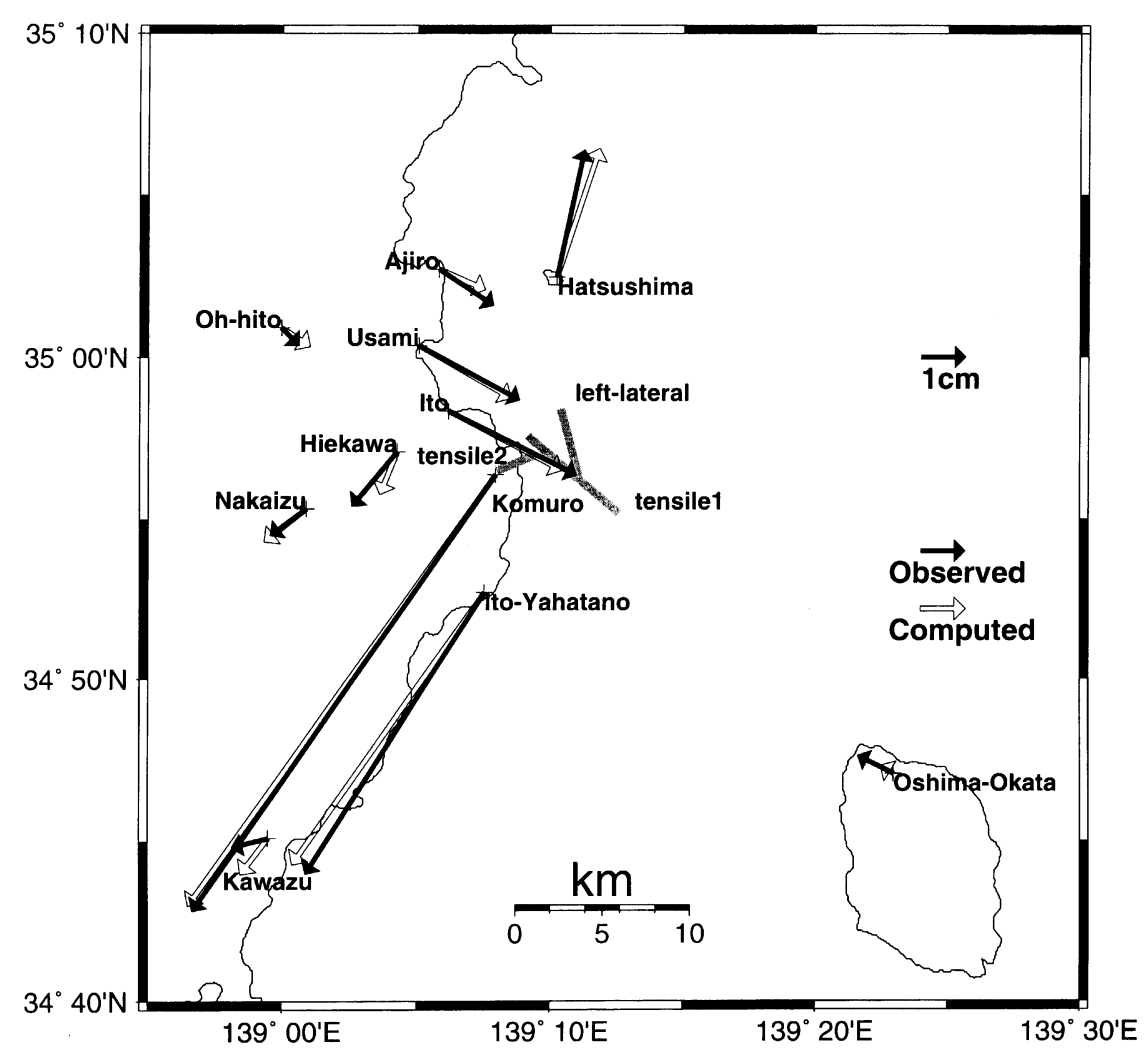

Fig. 3. Horizontal displacements measured by the nationwide GPS network of Geographical Survey Institute (1997). The solid arrows represent the observational results, and the open arrows represent the computed displacements of our elastic deformation model. The thick gray lines indicate the position of the faults determined in our modeling.

1996, after the October 1996 earthquake swarm, and in March 1997, after the March 1997 activity (Fig. 4). Prominent uplifts up to $3 \mathrm{~cm}$ were found near the center of the Ito City.

The EDM network has been surveyed every day at several sites around Ito since 1989 (Tsuneishi, 1991, 1997). During the March swarm, it revealed a fine structure of the crustal movement (Fig. 5).

We use the data described above to model the ground deformation caused by three faults buried in an elastic half-space. The geometrical fault parameters (Table 3 ) are determined in two steps. First we use the GPS and leveling data to model large scale $(\sim 10 \mathrm{~km})$ ground deformation, which we attribute to a strike-slip fault and a tensile fault. Second we use the EDM data to model small scale $(\sim 1 \mathrm{~km})$ ground deformation near the Ito City, which we ascribe to another tensile fault.

In the first step, we model the large-scale ground deformation with two faults. We put the first strike-slip fault near the center of the region of swarm epicenters because most of the earthquakes have strike-slip type mechanisms. We further put the second tensile fault near the swarm region. The fault is required to explain large horizontal movements away from the swarm region, which are evident at the Komuro-yama GPS station, for example. To obtain the fault parameters, we minimize the variance given by

$$
V_{1}=\sum_{\mathrm{GPS}} \frac{\left(u_{x}^{\mathrm{obs}}-u_{x}^{\mathrm{calc}}\right)^{2}+\left(u_{y}^{\mathrm{obs}}-u_{y}^{\mathrm{calc}}\right)^{2}}{\sigma_{\mathrm{GPS}}^{2}}
$$

$$
+\sum_{\text {leveling }} \frac{\left(u_{z}^{\mathrm{obs}}-u_{z}^{\mathrm{calc}}\right)^{2}}{\sigma_{\text {leveling }}^{2}}
$$

where $\left(u_{x}, u_{y}, u_{z}\right)$ are the displacements in the east, north, vertical direction, respectively, and $\sigma$ is their measurement errors. The errors $\sigma_{\mathrm{GPS}}$ and $\sigma_{\text {leveling }}$ are set to $6 \mathrm{~mm}$ and $5 \mathrm{~mm}$, respectively. The superscripts "obs" and "calc" signify the observed and calculated values, respectively. The Poisson ratio of $1 / 4$ is used throughout the calculation. We search the optimum fault parameters by calculating the variance for all the grid points in the range shown in Table 3 so that the global minimum should be attained. The optimum parameters will serve as an initial guess in the following step.

In the second step, we put a small tensile fault near the western edge of the tensile fault introduced in the first step. The fault is required to explain the EDM results. We minimize the variance given by

$$
\begin{aligned}
V_{2}= & \sum_{\mathrm{GPS}} \frac{\left(u_{x}^{\mathrm{obs}}-u_{x}^{\mathrm{calc}}\right)^{2}+\left(u_{y}^{\mathrm{obs}}-u_{y}^{\mathrm{calc}}\right)^{2}}{\sigma_{\mathrm{GPS}}^{2}} \\
& +\sum_{\text {leveling }} \frac{\left(u_{z}^{\mathrm{obs}}-u_{z}^{\text {calc }}\right)^{2}}{\sigma_{\text {leveling }}^{2}} \\
& +\sum_{\mathrm{EDM}} \frac{\left(\Delta l^{\mathrm{obs}}-\Delta l^{\text {calc }}\right)^{2}}{\sigma_{\mathrm{EDM}}^{2}}
\end{aligned}
$$

where $\Delta l$ is the distance change between the EDM sites. We assign $1 \mathrm{~cm}$ to $\sigma_{\mathrm{EDM}}$. The parameters of the first two faults are also slightly adjusted in this step. 


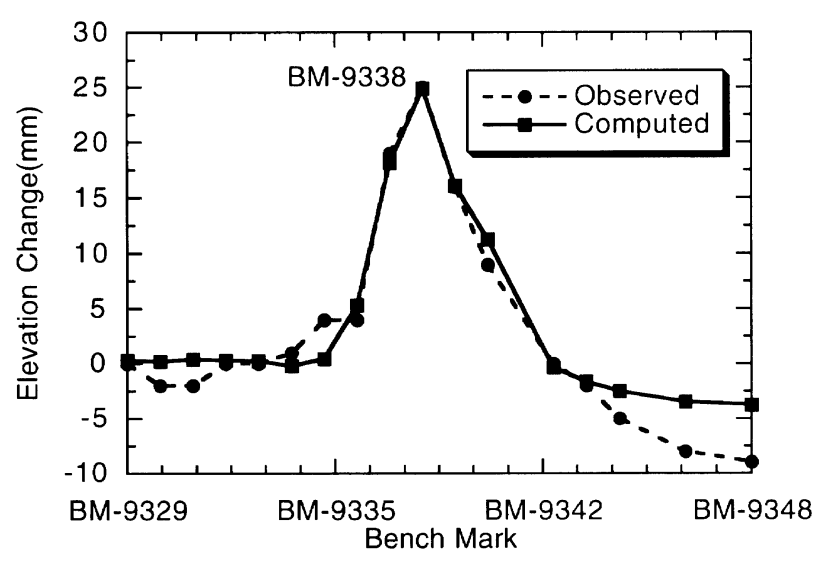

(a)

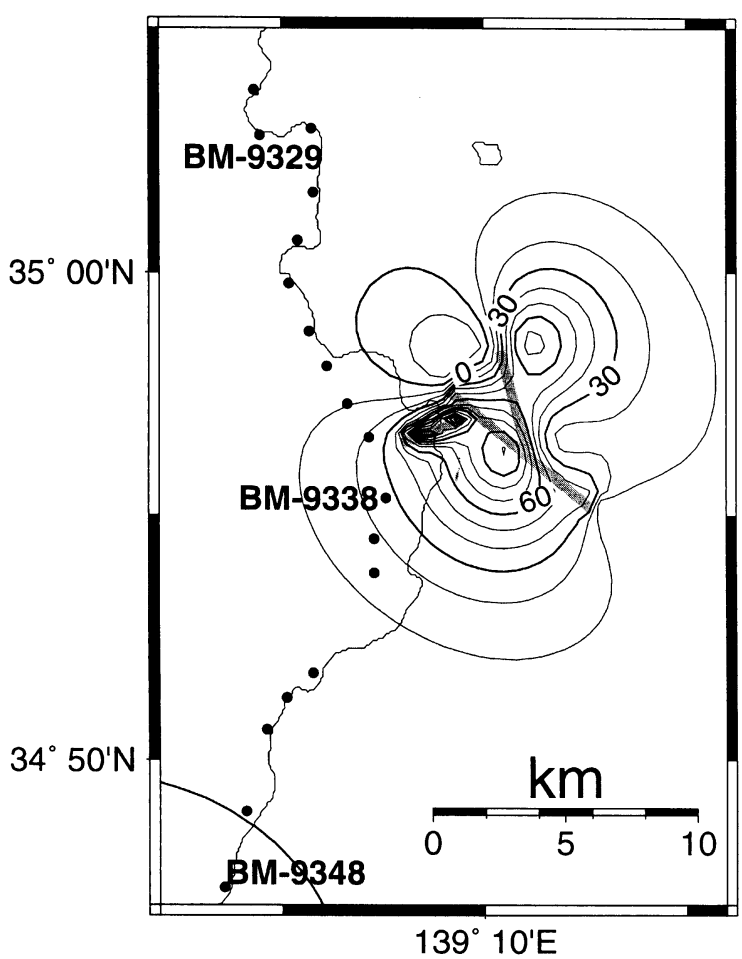

(b)

Fig. 4. Vertical displacements measured by the leveling of Geographical Survey Institute (1997). (a) Comparison between the observations and the model results. The solid circles show the observed elevation changes of benchmarks. The solid squares show the results of our model calculation. (b) Contour map of the vertical displacements derived from our model. The unit is $\mathrm{mm}$. The thick gray lines indicate the position of the faults determined in our modeling.

Table 3 shows the optimum fault parameters. Notice that the optimum dip angles are $90^{\circ}$ (vertical) for all the faults. The verticality signifies that the prevalent differential stress is horizontal in this area.

Figures 3-5 show the calculated ground displacements together with the locations of the faults. The observations are reproduced well by the fault model.

We present in Fig. 6 the variance $V_{2}$ as a function of important fault parameters. The variance shows a steep minimum

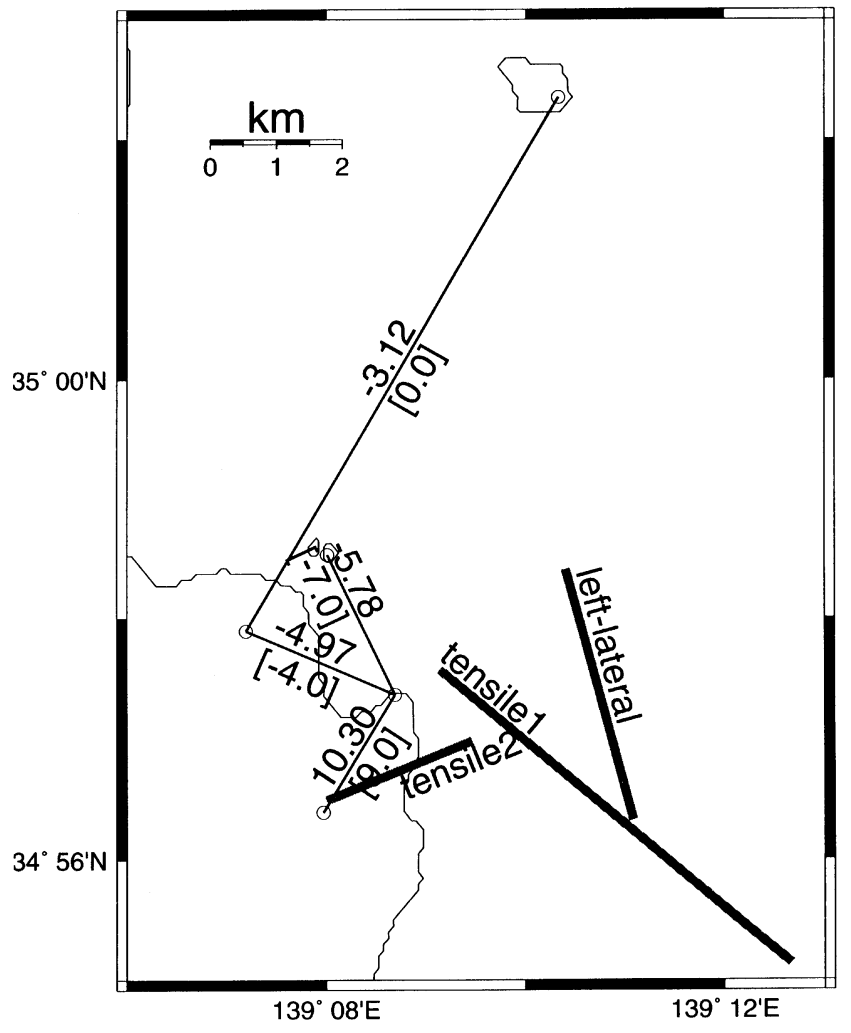

Fig. 5. Distance changes between several points near Ito measured by Tsuneishi (1997). The lines show the measurement lines. The numbers on the line show the results of our model. The numbers in square brackets show the observations. The unit is $\mathrm{cm}$. The thick gray lines indicate the position of the faults in our model.

as a function of the parameters. This signifies that the fault geometry and displacements are tightly constrained. The minimum value of the variance is 22.4 , which we expect to be 20 for the $\chi^{2}$ distribution. The two values agree within the expected standard deviation of $2 \times 20=40$. The expected variance 20 equals the degree of freedom. It is given by the number of the data 44 (18 leveling data, 4 EDM data, and $11 \times 2$ GPS data) minus the number of the fault parameters 24 (8 parameters for each of the three faults).

3.2 Determination of the density of fault-filling matter

Next, we use the gravity data and the fault parameters obtained above to estimate the density of the material which would have filled the tensile faults. We minimize the variance given by

$$
V_{3}=\sum_{\text {gravity }} \frac{\left(\Delta g^{\text {obs }}-\Delta g^{\text {calc }}\right)^{2}}{\sigma_{\text {gravity }}^{2}},
$$

where $\Delta g$ is the gravity change. The gravity measurement error $\sigma_{\text {gravity }}$ is set to $7 \mu$ gal. We did not use the data denoted by asterisks in Table 2 because it is evident that they are not associated with the movement of the faults. The value of $2.67 \mathrm{~g} / \mathrm{cm}^{3}$ is used for the density of the surrounding medium in the calculation.

Figure 7 shows the change of the variance $V_{3}$ as a function of the densities which would have filled the two tensile faults. For the larger fault, the density is likely to be below $1.5 \mathrm{~g} / \mathrm{cm}^{3}$. For the smaller fault, the density cannot be constrained. The 
Table 3. Optimum parameters for the three faults.

Strike-slip fault (left lateral)

\begin{tabular}{|c|c|c|}
\hline & Grid search range & Optimum value \\
\hline \multirow[t]{2}{*}{ Location of the western edge } & $139.160^{\circ} \mathrm{E}-139.205^{\circ} \mathrm{E}$ & $139.175^{\circ} \mathrm{E}$ \\
\hline & $34.965^{\circ} \mathrm{N}-34.985^{\circ} \mathrm{N}$ & $34.970^{\circ} \mathrm{N}$ \\
\hline Strike angle & $\mathrm{N} 160^{\circ} \mathrm{E}-\mathrm{N} 180^{\circ} \mathrm{E}$ & $\mathrm{N} 165^{\circ} \mathrm{E}$ \\
\hline Length & $3.0-8.0 \mathrm{~km}$ & $4.0 \mathrm{~km}$ \\
\hline Width & $3.0-6.0 \mathrm{~km}$ & $4.0 \mathrm{~km}$ \\
\hline Dip angle & $70^{\circ}-100^{\circ}$ & $90^{\circ}$ \\
\hline Depth of the upper edge & $1.0-4.0 \mathrm{~km}$ & $1.0 \mathrm{~km}$ \\
\hline Left-lateral dislocation & $0.5-0.9 \mathrm{~m}$ & $0.8 \mathrm{~m}$ \\
\hline \multicolumn{3}{|l|}{ Tensile fault-1 (large) } \\
\hline & Grid search range & Optimum value \\
\hline \multirow[t]{2}{*}{ Location of the western edge } & $139.070^{\circ} \mathrm{E}-139.210^{\circ} \mathrm{E}$ & $139.154^{\circ} \mathrm{E}$ \\
\hline & $34.920^{\circ} \mathrm{N}-35.000^{\circ} \mathrm{N}$ & $34.956^{\circ} \mathrm{N}$ \\
\hline Strike angle & $\mathrm{N} 100^{\circ} \mathrm{E}-\mathrm{N} 170^{\circ} \mathrm{E}$ & $\mathrm{N} 130^{\circ} \mathrm{E}$ \\
\hline Length & $3.0-11.0 \mathrm{~km}$ & $7.0 \mathrm{~km}$ \\
\hline Width & $2.0-7.0 \mathrm{~km}$ & $6.0 \mathrm{~km}$ \\
\hline Dip angle & $60^{\circ}-110^{\circ}$ & $90^{\circ}$ \\
\hline Depth of the upper edge & $0.0-6.0 \mathrm{~km}$ & $0.0 \mathrm{~km}$ \\
\hline Tensile opening & $0.2-0.7 \mathrm{~m}$ & $0.3 \mathrm{~m}$ \\
\hline $\begin{array}{l}\text { Density of the material } \\
\text { which filled the cavity }\end{array}$ & $0.0-3.63 \mathrm{~g} / \mathrm{cm}^{3}$ & $0.0 \mathrm{~g} / \mathrm{cm}^{3}$ \\
\hline \multicolumn{3}{|l|}{ Tensile fault-2 (small) } \\
\hline & Grid search range & Optimum value \\
\hline \multirow[t]{2}{*}{ Location of the western edge } & $139.120^{\circ} \mathrm{E}-139.150^{\circ} \mathrm{E}$ & $139.135^{\circ} \mathrm{E}$ \\
\hline & $34.935^{\circ} \mathrm{N}-34.960^{\circ} \mathrm{N}$ & $34.938^{\circ} \mathrm{N}$ \\
\hline Strike angle & $\mathrm{N} 60^{\circ} \mathrm{E}-\mathrm{N} 80^{\circ} \mathrm{E}$ & $\mathrm{N} 68^{\circ} \mathrm{E}$ \\
\hline Length & $1.0-4.0 \mathrm{~km}$ & $2.4 \mathrm{~km}$ \\
\hline Width & $0.2-4.0 \mathrm{~km}$ & $0.4 \mathrm{~km}$ \\
\hline Dip angle & $60^{\circ}-120^{\circ}$ & $90^{\circ}$ \\
\hline Depth of the upper edge & $0.0-4.0 \mathrm{~km}$ & $0.0 \mathrm{~km}$ \\
\hline Tensile opening & $0.1-0.8 \mathrm{~m}$ & $0.35 \mathrm{~m}$ \\
\hline $\begin{array}{l}\text { Density of the material } \\
\text { which filled the cavity }\end{array}$ & $0.0-3.63 \mathrm{~g} / \mathrm{cm}^{3}$ & not constrained \\
\hline
\end{tabular}

smallness of the density in the larger fault implies that it would have contained large amount of gas or water. The minimum value of the variance is 10.8 , while its expected value is 20 , which is given by the number of the data 22 minus the number of the density parameters 2 . The calculated variance is about half the expected one, but the difference is within the expected standard deviation of 40 . The smallness of the calculated value may signify that the estimated error of $7 \mu \mathrm{gal}$ is an overestimate.

Previous analyses of gravity changes related to fissure eruptions also revealed the intrusion of low-density matters. Okubo and Watanabe (1989) analyzed the gravity changes associated with the 1986 fissure eruption of the 1986 IzuOshima Volcano to find that the material which filled the 


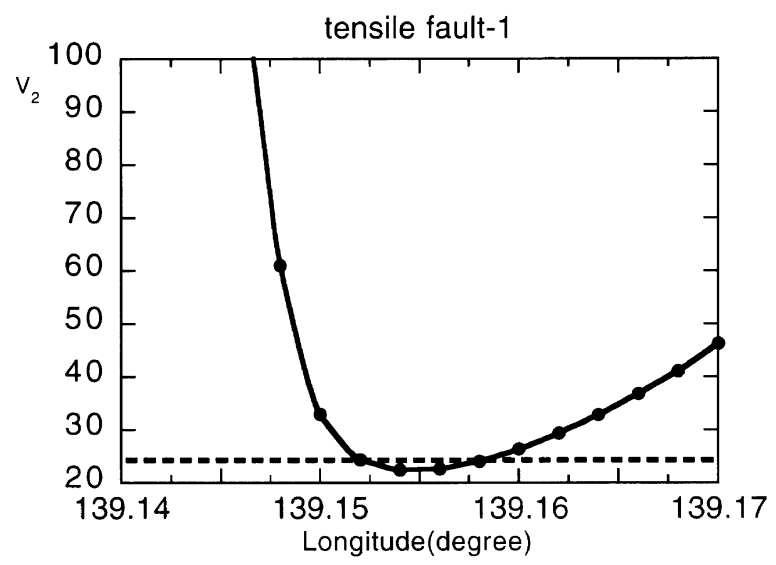

(a)

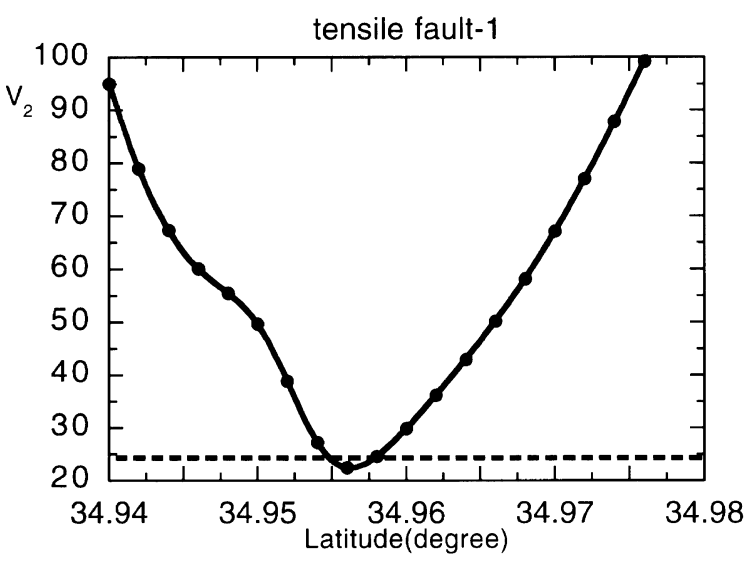

(b)

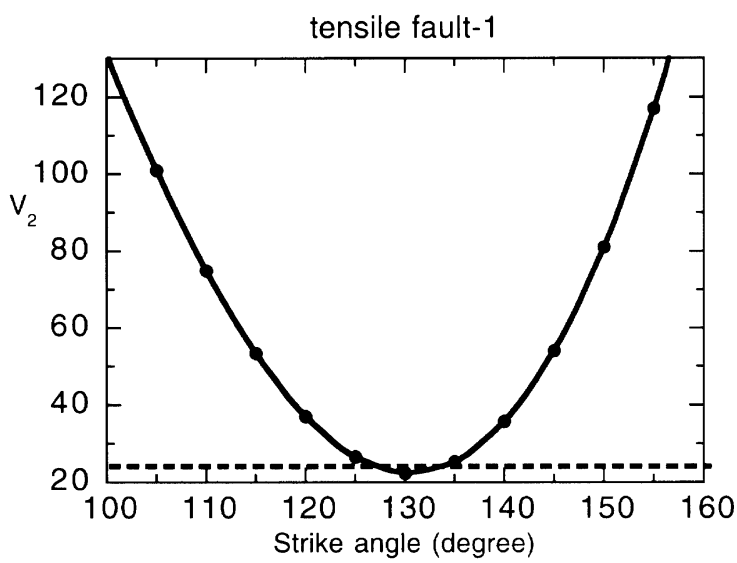

(c)

Fig. 6. Variance $V_{2}$ as a function of several important parameter values. The minimum value $V_{\min }$ of the variance is 22.4 . The broken line indicates the value $V_{\min }+2$, for which the likelihood is reduced by $e^{-1}$. (a) Variance against the longitude of the western edge of the tensile fault 1. (b) Variance against the latitude of the western edge of the tensile fault 1. (c) Variance against the strike angle of the tensile fault 1 .

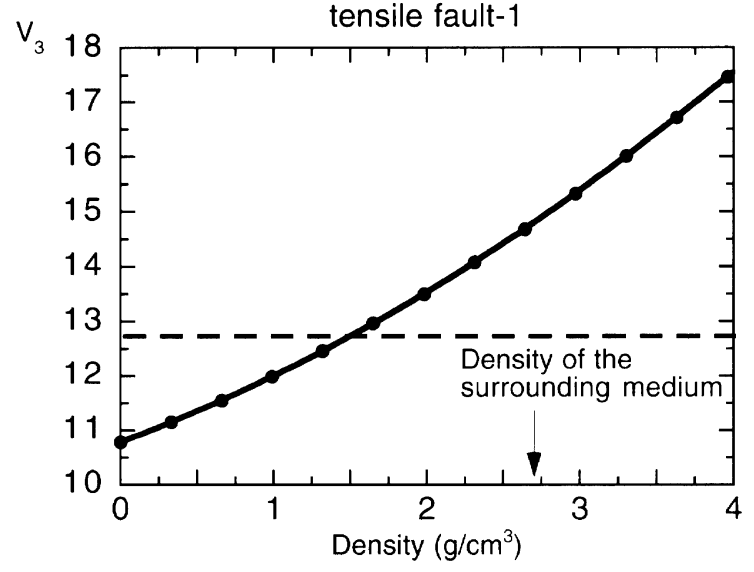

(a)

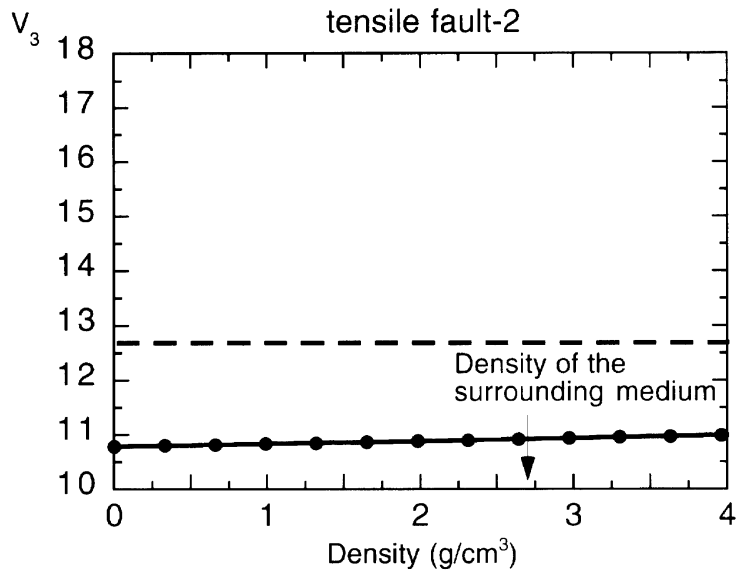

(b)

Fig. 7. Variance $V_{3}$ as a function of the densities of the materials which filled the two tensile faults. The minimum value $V_{\min }$ of the variance is 10.8 . The broken line indicates the value $V_{\min }+2$, for which the likelihood is reduced by $e^{-1}$. (a) Variance against the density of the material which filled the tensile fault 1 . It shows that the density is below $1.5 \mathrm{~g} / \mathrm{cm}^{3}$. (b) Variance against the density of the material which filled the tensile fault 2. It shows that the density cannot be constrained.

fissure zone had a density of $0.8 \pm 0.5 \mathrm{~g} / \mathrm{cm}^{3}$. Okubo et al. (1991) showed that the matter which filled the tensile crack related to the 1989 Teishi-Knoll Eruption had almost zero density. Thus the intrusion of gas or water into fissures would be a common phenomenon in volcanic activities.

Figure 8 shows the contour map of calculated gravity change with the densities of the intruding material set to zero. It displays that the gravity changes in the region 1 results only from the motion of the faults obtained from GPS, leveling, and EDM data. The gravity changes in the region 2 and 3 require other explanations.

\section{Discussion}

We shall discuss the characteristics of the crustal movements and gravity changes associated with the March earthquake swarm in relation to the tectonic environment. Our discussion on the tectonics is based on the tectonic model of 


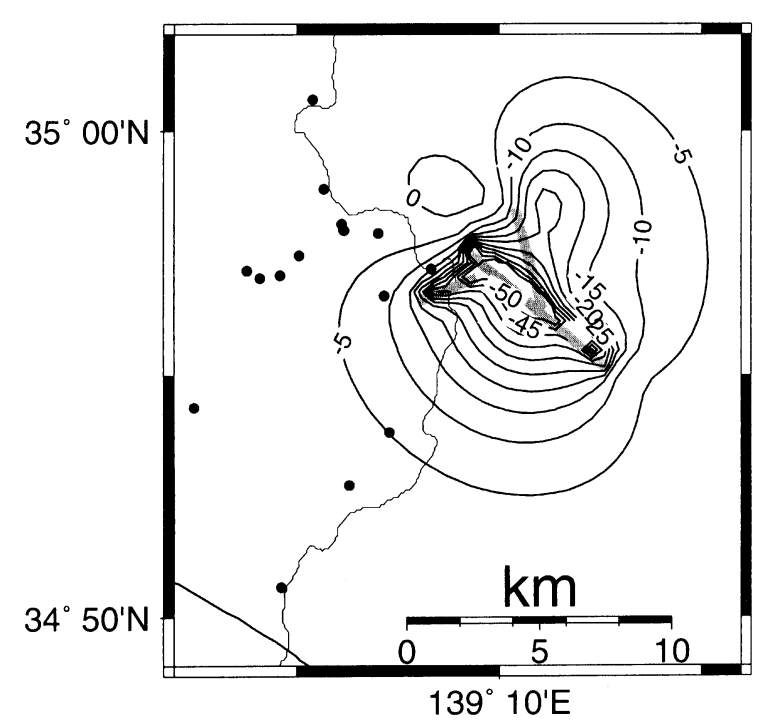

Fig. 8. Contour map of the calculated gravity change associated with the fault motion. The unit is $\mu$ gal. The densities of the materials which filled the two tensile faults are set to zero. The thick gray lines indicate the position of the faults.

Koyama and Umino (1991) and Koyama (1993).

The crustal displacements around Ito are explained well by the three-fault model: a strike-slip fault and two tensile faults. The principal part is due to the larger tensile fault that extends to the NW-SE direction. This type of fault is often invoked to explain the crustal movement of this area associated with earthquake swarms (Okada and Yamamoto, 1991a,b; Okubo et al., 1991; Tada and Hashimoto, 1991), and would be related to volcanic activities. It is also consistent with the NW-SE vent alignments of the Higashi-Izu monogenetic volcanos (Aramaki and Hamuro, 1977; Koyama and Umino, 1991; Koyama et al., 1995). This alignment of the fissures is interpreted as a result of NW-SE compressive and NE-SW tensile stress field of this region. The stress field itself can be understood as the result of the collision of the Philippine Sea plate with the Japan Island and the release of stress by the West-Sagami-Bay Fracture (Koyama and Umino, 1991).

In Section 2, we have identified three regions where gravities changed significantly. We shall discuss the characteristics of each region in the following.

The three-fault model explains the gravity changes in the region 1 very well, and reveals that the density of the material that filled the larger tensile fault is very small. The smallness implies that it contained large amount of exsolved gas or water. Such a low density is consistent with the shallowness of the fault, because most of the water would exsolve from the magma at depths shallower than $1 \mathrm{~km}$ (e.g. Woods, 1995). The strength of the uppermost crust, in this case, prevented the highly vesiculated magma from erupting.

The complex pattern of the gravity changes in the region 2 may indicate the intrusion of magma or fluid to the shallow part beneath Ito. The shallow intrusion is also suggested by the existence of the smaller tensile fault in our three-fault model. The fault is very shallow and extends to the land region.
On the other hand, the gravity decrease in the region 3 remains puzzling. Lack of other observations in this area prohibits detailed modeling. Similar decreases were observed in 1994 and 1995. They can be associated with the earthquake swarms of March 1994 and October 1995, respectively. Hence, the gravity decrease in the mountain area of the Izu Peninsula would commonly accompany earthquake swarms near Ito. An explanation for the gravity decrease may be constructed based on the block rotation model of Koyama and Umino (1991). They proposed that the northeastern region of the Izu Peninsula is composed of slivers which are rotated counterclockwise due to the left-lateral shearing motion. They assigned the western boundary of the slivers to the Kita-Izu Fault system, which extends to the center of the gravity decrease (Fig. 1). As the slivers move, a large deformation in the deeper parts of the Kita-Izu Fault system is expected. This may have given rise to the observed gravity decrease.

Acknowledgments. We thank Daniel Johnson and an anonymous reviewer for their helpful comments. We are grateful to the Ito City Office for providing us a room for the absolute gravity measurements. We thank Geographical Survey Institute for lending us the dropping chamber of the FG5 \#104 when our instrument was in trouble. We thank Akito Araya for his help during the gravity measurement. This study was supported by the Earthquake Research Institute cooperative research program (1997-B0-01) and by a Grant in Aid for Scientific Research (A)(1) from the Japanese Ministry of Education, Science, Sports and Culture (No. 08304028).

\section{References}

Aramaki, S. and K. Hamuro, Geology of the Higashi-Izu monogenetic volcano group, Bull. Earthquake Res. Inst. Univ. Tokyo, 52, 235-278, 1977 (in Japanese with English abstract).

Becker, M., E. Groten, A. Lambert, J. O. Liard, and S. Nakai, An intercomparison of LaCoste and Romberg Model-D gravimeters: results of the International D-meter Campaign, 1983, Geophys. J. R. astr. Soc., 89, 499-526, 1987.

Earthquake Research Institute, Seismic activities in the Izu Peninsula and its vicinity (February, 1997-April, 1997), Report of the Coordinating Committee for Earthquake Prediction, 58, 239-249, 1997 (in Japanese).

Geographical Survey Institute, Crustal movements in the Izu peninsula and its vicinity, Report of the Coordinating Committee for Earthquake Prediction, 58, 290-311, 1997 (in Japanese).

Hagiwara, Y., H. Tajima, S. Izutsuya, K. Nagasawa, I. Murata, S. Okubo, and T. Endo, Gravity change in the Izu Peninsula in the last decade, $J$. Geod. Soc. Japan, 31, 220-235, 1985 (in Japanese with English abstract).

Hori, S., Recent swarm activity around the Izu peninsula, Report of the National Research Center for Disaster Prevention, 43, 127-167, 1989 (in Japanese with English abstract).

Imamura Laboratory and Seismological Laboratory, On the Ito earthquake (part 2), Zisin, 2, 281-300, 1930 (in Japanese).

Ishimoto, M. and R. Takahashi, Séismes d'Ito et l'observation sur les variations de l'inclinaison de la surface terrestre, Bull. Earthquake Res. Inst. Tokyo Imperial Univ., 8, 427-458, 1930 (in Japanese with French abstract).

Japan Meteorological Agency, Seismic activity in and around the Izu Peninsula (November, 1996-April, 1997), Report of the Coordinating Committee for Earthquake Prediction, 58, 229-238, 1997 (in Japanese).

Koyama, M., Volcanos and tectonics of the Izu Peninsula, Kagaku, 63, 312-321, 1993 (in Japanese).

Koyama, M. and S. Umino, Why does the Higashi-Izu monogenetic volcano group exist in the Izu Peninsula?: Relationships between late Quaternary volcanism and tectonics in the northern tip of the Izu-Bonin arc, J. Phys. Earth, 39, 391-420, 1991.

Koyama, M., Y. Hayakawa, and F. Arai, Eruptive history of the HigashiIzu monogenetic volcano field 2: mainly on volcanoes older than 32,000 years ago, Bull. Volcan. Soc. Japan, 40, 191-209, 1995 (in Japanese with 
English abstract).

Kuno, H., Geology and petrology of Omuro-yama volcano group, North Izu, J. Fac. Sci. Univ. Tokyo, Sect. 2, 9, 241-265, 1954.

Mogi, K., Irreversible change in the recent crustal activity of the western part of Izu Peninsula, Chikyuu Monthly, 13, 55-62, 1991 (in Japanese).

Nakamura, K., K. Shimazaki, and N. Yonekura, Subduction, bending, and eduction. Present and Quaternary tectonics of the northern border of the Philippine Sea plate, Bull. Soc. Geol. France, 26, 221-243, 1984.

Nasu, N., Observation of the Ito earthquake, Zisin, 2, 301-306, 1930 (in Japanese).

Nasu, N., Recent seismic activities in the Idu Peninsula, Bull. Earthquake Res. Inst. Tokyo Imperial Univ., 13, 400-416, 1935.

Niebauer, T. M., G. Sasagawa, J. E. Faller, R. Hilt, and F. J. Klopping, A new generation of absolute gravimeters, Metrologia, 32, 159-180, 1995.

Okada, Y., Surface deformation due to shear and tensile faults in a half-space, Bull. Seism. Soc. Amer., 75, 1135-1154, 1985.

Okada, Y. and E. Yamamoto, A model for the 1989 seismo-volcanic activity off Ito, central Japan, derived from crustal movement data, J. Phys. Earth, 39, 177-195, 1991a.

Okada, Y. and E. Yamamoto, Dyke intrusion model for the 1989 seismovolcanic activity off Ito, central Japan, J. Geophys. Res., 96, 10361-10376, $1991 b$

Okubo, S., Potential and gravity changes raised by point dislocations, Geophys. J. Int., 105, 573-586, 1991.

Okubo, S., Potential and gravity changes due to shear and tensile faults in a half-space, J. Geophys. Res., 97, 7137-7144, 1992.

Okubo, S. and H. Watanabe, Gravity change caused by a fissure eruption, Geophys. Res. Lett., 16, 445-448, 1989.

Okubo, S., Y. Hirata, M. Sawada, and K. Nagasawa, Gravity change caused by the 1989 earthquake swarm and submarine eruption off Ito, Japan-
Test on the magma intrusion hypothesis, J. Phys. Earth, 39, 219-230 1991.

Okubo, S., S. Yoshida, T. Sato, Y. Tamura, and Y. Imanishi, Verifying the precision of a new generation absolute gravimeter FG5-Comparison with superconducting gravimeters and detection of oceanic loading tide, Geophys. Res. Lett., 24, 489-492, 1997.

Tada, T. and M. Hashimoto, Anomalous crustal deformation in the northeastern Izu Peninsula and its tectonic significance-tension crack model, J. Phys. Earth, 39, 197-218, 1991.

Torge, W., Gravimetry, 465pp., Walter de Gruyter, Berlin, 1989.

Tsukahara, H. and R. Ikeda, Hydraulic fracturing stress measurements and in-situ stress field in the Kanto-Tokai area, Japan, Tectonophysics, 135, 329-345, 1987.

Tsuneishi, Y., Continuous monitoring of crustal activity in east Izu Peninsula by automatic electronic distance measurement, J. Phys. Earth, 39, 131139, 1991.

Tsuneishi, Y., EDM observation on the 1997, March, Off-Ito swarm earthquakes, Report of the Coordinating Committee for Earthquake Prediction, 58, 272-277, 1997 (in Japanese).

Tsuya, H., On the geologic structure of Ito district, Idu, Bull. Earthquake Res. Inst. Tokyo Imperial Univ., 8, 409-426, 1930.

Ukawa, M., Collision and fan-shaped compressional stress pattern around the Izu block at the northern edge of the Philippine Sea plate, J. Geophys. Res., 96, 713-733, 1991.

Woods, A. W., The dynamics of explosive volcanic eruptions, Rev. Geophys., 33, 495-530, 1995.

S. Yoshida (e-mail: yoshida@eps.nagoya-u.ac.jp), G. Seta, S. Okubo, and S. Kobayashi 